\title{
Gene flow across a chromosomal tension zone. I. Relicts of ancient hybridization
}

\author{
A. D. Marchant, \\ M. L. Arnold* and \\ P. Wilkinson
}

\author{
Population Genetics Group, Research School of \\ Biological Sciences, Australian National University, \\ PO Box 475, Canberra ACT 2601, Australia.
}

Two parapatric subspecies of grasshopper with extensive karyotypic differences form a hybrid zone in which the change-over of chromosomal characters occurs over a distance of $800 \mathrm{~m}$. Asymmetrical introgression of restrictionfragment markers of the nuclear ribosomal RNA genes, and mitochondrial DNA, and also of four enzyme electromorphs is reported. These markers were found to have introgressed for varying distances (100-300 km) to the north of the present-day hybrid zone. It is proposed that these markers are relicts of ancient hybridization between the Moreton and Torresian subspecies in an area where only the Torresian form (as defined by karyotype) is now found, and that the two taxa have maintained their chromosomal distinction despite prolonged hybridization and the geographic displacement of the Moreton subspecies by the Torresian form.

\section{INTRODUCTION}

Studies of two karyotypically distinct and parapatric subspecies of the Australian grasshopper Caledia captiva ("Torresian" and "Moreton") have demonstrated partial reproductive isolation, manifest as total embryonic inviability of $F_{2}$ hybrids, and an approximately $50 \%$ reduction in backcross viability (Shaw and Wilkinson, 1980). This pattern of hybrid breakdown appears to be responsible for the maintenance of a narrow ( $c a$. $800 \mathrm{~m}$ ) hybrid zone along the $200 \mathrm{~km}$ common boundary of their ranges (Shaw et al., 1980). Shaw et al. (1982) and Coates and Shaw (1982) found the hybrid breakdown to be caused partially by differences in centromere positions of homologous chromosomes from the two taxa, which alter the distribution of positions of crossing-over in heterozygous meiosis; this crossing-over in turn is presumed to disrupt physically integrated gene complexes. The effect of the centromere position differences has been estimated to account for 46 per cent of the inviability of Torresian/Moreton $F_{2}$ hybrids; Coates and Shaw (1984) suggested that the remaining hybrid breakdown may be associated with "genic" differences between the taxa.

\footnotetext{
* Present address: Department of Biochemistry, Louisiana State University, Baton Rouge, Louisiana, U.S.A.
}

Previously, allozyme differences (Moran et al., 1980; Daly et al., 1981), restriction-fragment length polymorphisms (RFLPs) of the ribosomal DNA (rDNA) (Arnold et al., 1987a) and mitochondrial DNA (mtDNA) (Marchant, 1988), and variation in the cytological distribution and associated DNA sequences of heterochromatin (Shaw et al., 1976; Arnold and Shaw, 1985; Arnold, 1986) which distinguish Torresian from Moreton, have been described. The distributions of these markers along transects taken across the hybrid zone have been studied (Moran, 1979; Shaw et al., 1979; Shaw et al., 1985; Arnold et al., 1987a; Marchant et al., in preparation; Moran and Shaw, 1977). These analyses have found that the geographical change-over from insects having Torresian allozyme, rDNA and mtDNA markers, to those having Moreton markers, corresponds nearly to the null points shown by the frequencies of the chromosome structural markers (Shaw et al., 1979; Shaw et al., 1985). No introgression of Moreton chromosomes has ever been detected outside the narrow zone of hybridization (Shaw et al., 1987), but Moreton rDNA, mtDNA and allozyme markers are present in some Torresian populations (Arnold et al., $1987 a$; Marchant 1987, 1988; Marchant et al., in preparation).

In this paper, we present data from an analysis of rDNA, mtDNA, allozyme and chromosomal 
characters of $C$. captiva populations from an area outside the defined hybrid zone, in the previously described geographical range of the Torresian subspecies (Shaw et al., 1980). Marchant (1988) has already reported the presence of Moreton mtDNA markers from a number of these populations; our present data, in conjunction with this, provide evidence for an ancient hybridization between the two subspecies in an area now occupied exclusively by insects having Torresian karyotypic markers. We argue that the data support the idea of intra-, and possibly inter-chromosomal coadaptation (see Shaw and Coates, 1983). We also discuss the possible contributions of selection, chance, and (in the case of rDNA) biased gene conversion, to the process of introgression.

\section{MATERIALS AND METHODS}

\section{Collection localities}

The geographical distributions of the various $C$. captiva taxa, including the Torresian and Moreton subspecies, have been described previously (Shaw et al., 1980). The populations examined in the present study are shown in fig. 1 and table 1 .

\section{Allozyme analysis}

Electrophoretic analysis of the enzymes glutamate oxalate transaminase 2 (GOT-2), isocitrate dehydrogenase 1 (IDH-1), mannose phosphate isomerase (MPI) and phosphoglucose isomerase (PGI), on cellulose acetate, was performed using buffers and staining reactions described by Moran et al. (1980) and Daly et al. (1981).

\section{DNA isolation and RFLP analysis}

Total nuclear and mtDNA was isolated from individual grasshoppers using the DNA isolation procedure described by Arnold et al. (1987b). RFLPs that are diagnostic for the Torresian and Moreton rDNA and mtDNA have been previously identified (Arnold et al., 1987a; Marchant, 1988). Cla I restriction digestion of total DNA followed by gel electrophoresis, transfer of the restricted DNA to Gene Screen (New England Nuclear) and hybridization to a ${ }^{32} \mathrm{P}$ nick-translated $0.8 \mathrm{~kb}$ rDNA sequence (Arnold et al., 1987a) were used to resolve the rDNA markers. The restriction endonucleases Msp I, Hae III, Hind III and Xba I were used to assay for mtDNA markers (as described

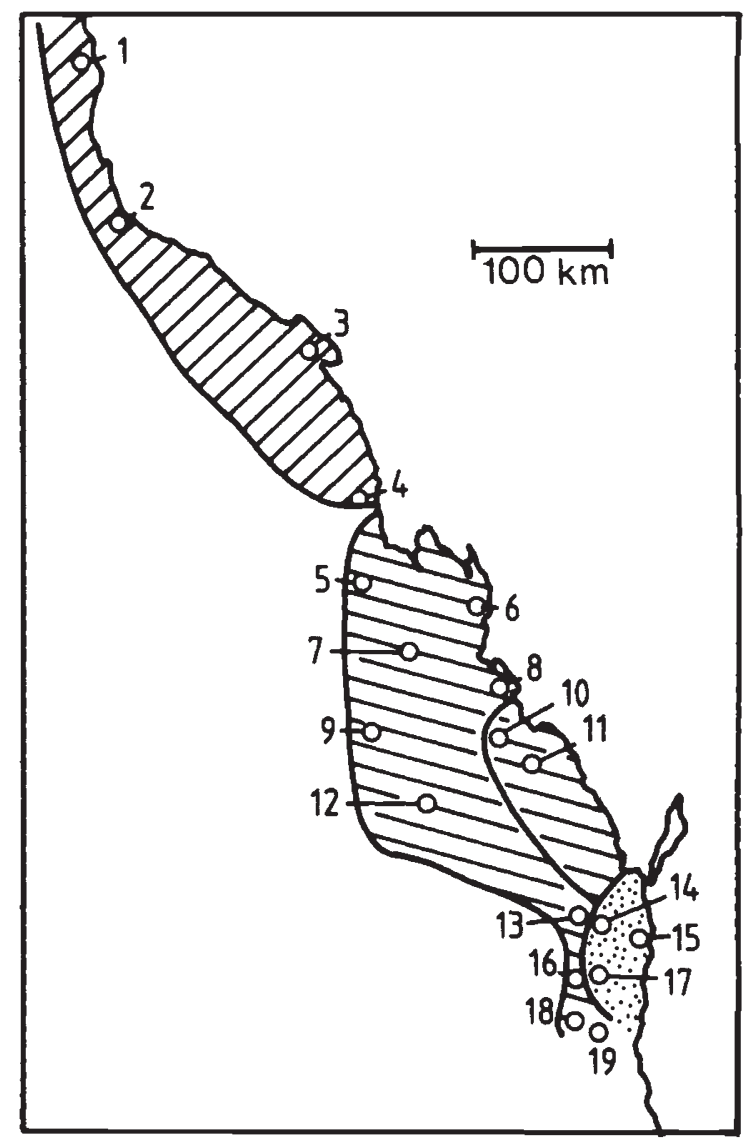

Figure 1 Populations sampled for rDNA, mtDNA and/or allozyme frequency (see Table 1 for population designations). /// designates region possessing Torresian rDNA, mtDNA and allozymes. $\backslash \backslash \backslash$ designates region possessing Torresian and Moreton rDNA. The stippled region contains chromosomally Moreton insects. Populations 10 and 11 are within the region fixed for Moreton mtDNA

by Marchant, 1988). The mtDNA RFLPs were identified by using probes synthesized from a set of clones representing the entire mitochondrial genome of $C$. captiva (Marchant, 1988).

\section{Chromosome analysis}

C-banded embryonic chromosome preparations from each of five egg pods, laid by insects collected from site 11 (fig. 1, table 1), were made using the technique described by Shaw et al. (1976). C-band chromosome analysis of grasshoppers from other sites within our study area has previously been carried out by Coates and Shaw (1984; Shaw, unpublished data). 
Table 1 Sample sizes, rDNA genotypes and mtDNA genotypes for 19 Caledia captiva populations

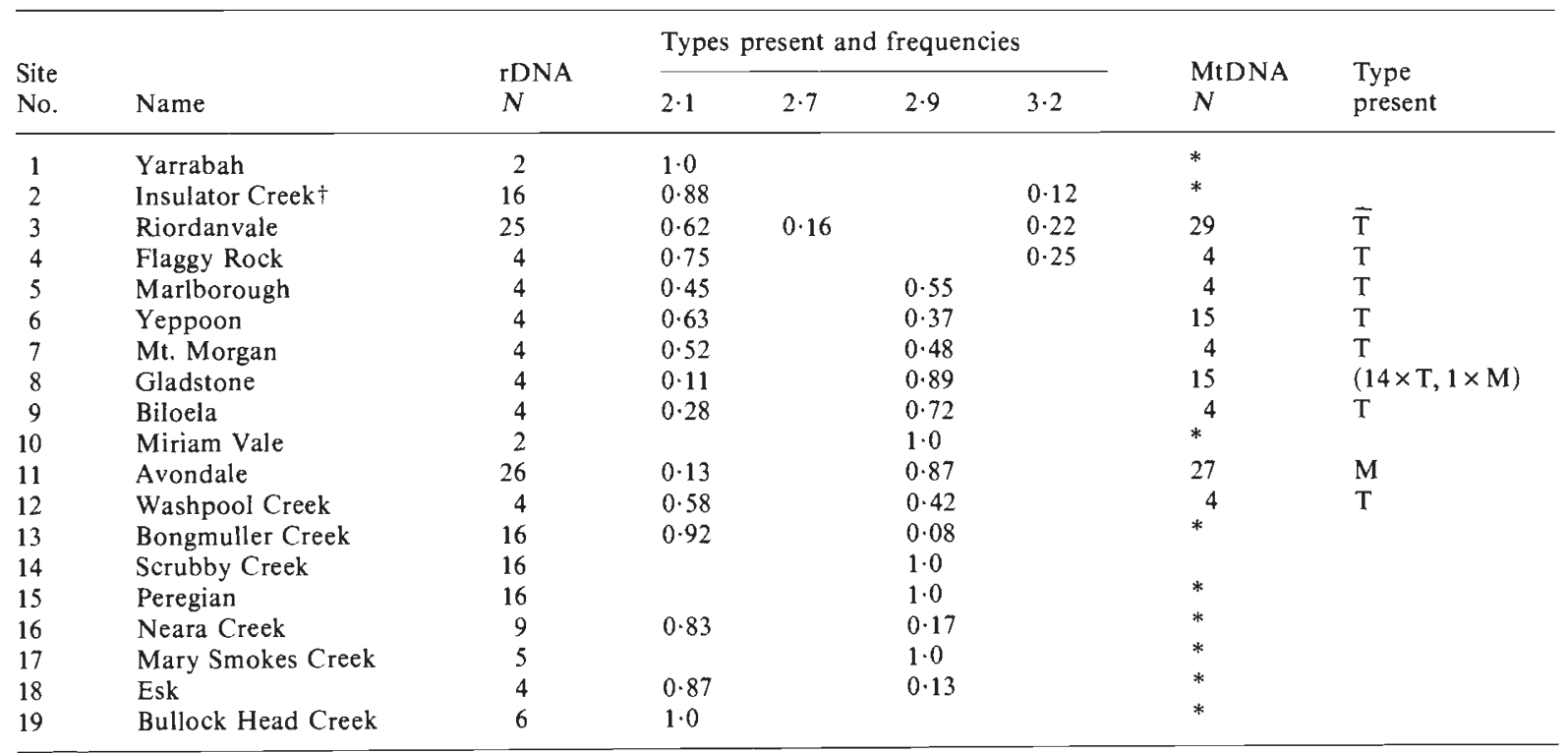

* Previously reported by Marchant (1987). Individuals for which the mtDNA type is reported in this paper are the same as those used for rDNA analysis.

$\dagger$ The 16 individuals from this site were the same as those which had Torresian mtDNA reported by Marchant (1988).

\section{RESULTS}

\section{Distribution of rDNA RFLP variants}

Arnold et al. (1987a) have described rDNA RFLP markers for the Moreton (" $2 \cdot 9$ " kb fragment) and the Torresian (" $2 \cdot 1$ " kb fragment) subspecies. These diagnostic RFLPs were shown to be present only in animals from their respective taxa, except near the hybrid zone between the two subspecies. In this region, the Moreton marker was found in high frequency in animals collected from populations on the Torresian side of the zone.

In addition to the 2.9 and $2 \cdot 1$ fragments, a " $3 \cdot 2$ " $\mathrm{kb}$ variant has been reported in a Torresian population located approximately $1200 \mathrm{~km}$ from the contact zone (Arnold et al., 1987a). In the present analysis we have detected four variants; these are the $2 \cdot 1,2 \cdot 7,2 \cdot 9$ and the $3 \cdot 2$ fragments (fig. 2). The frequencies of these markers in the 19 populations illustrated in fig. 1 are listed in table 1 .

The $2 \cdot 1$ fragment is present in populations $1-9$, $11-13,16,18$ and 19. Although each of these populations is within the geographic distribution of the Torresian subspecies (see Shaw et al., 1980), the frequency of the Torresian marker fragment varies enormously between populations $(0 \cdot 11-1 \cdot 0$., table 1). In addition, Torresian populations near the present-day hybrid zone $(13,16$ and 18$)$, as well as populations 5-12 located within a region north of the hybrid zone, all possess the Moreton 2.9 variant (table 1). Fig. 3 illustrates the frequency of the 2.9 and $2 \cdot 1$ variants in populations 5-19. The Torresian samples proximal to the hybrid zone demonstrate frequencies of the 2.9 Moreton RFLP that range from $0-0 \cdot 17$. In contrast, the Torresian populations 5-12 have much higher frequencies of the $2 \cdot 9$ variant $(0 \cdot 37-1 \cdot 0$, fig. 3$)$.

As stated previously, there were two additional rDNA RFLPs $(2 \cdot 7$ and $3 \cdot 2)$ that have been assayed in the present analysis. The $3 \cdot 2$ fragment was detected in three Torresian populations (samples 2-4) while the 2.7 variant was detected only in population 3. Although other fragments are present on the autoradiographs derived from the digested DNA, none of these have been found to be useful markers for the two subspecies (Arnold et al., $1987 a$ ).

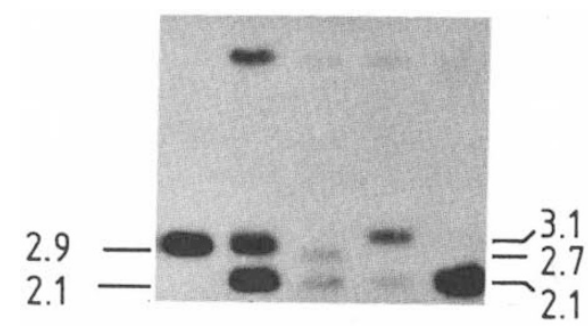

Figure 2 RFLPs of rDNA from Caledia captiva populations surveyed. 


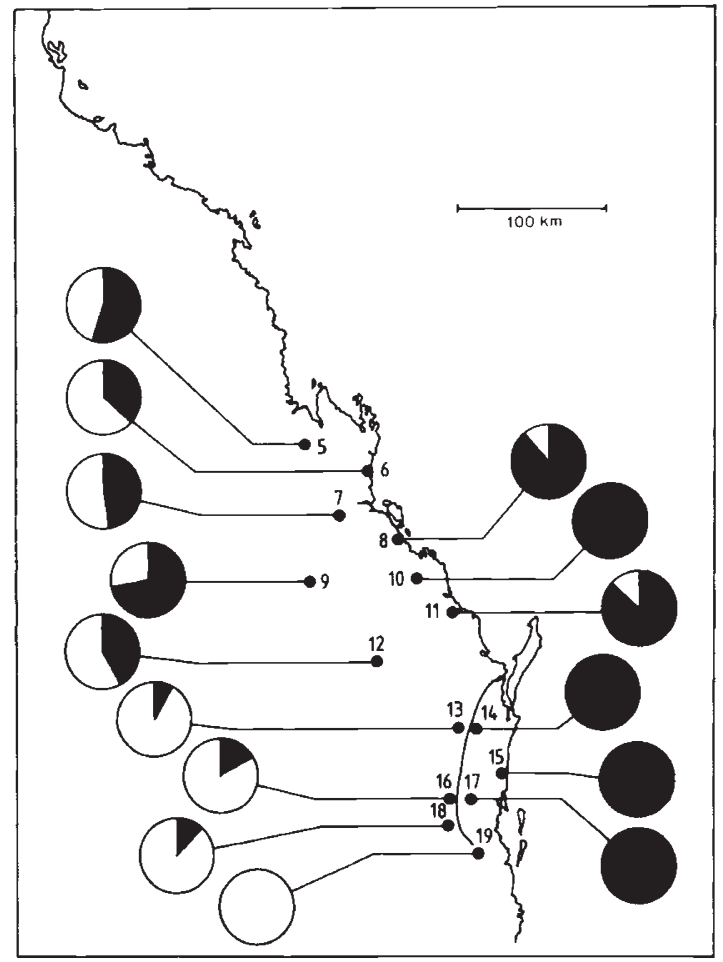

Figure 3 Frequency of the rDNA RFLPs 2.9 (darkened sector) and $2 \cdot 1$ (light sector) for populations $5-19$. Note the high frequency of the $2 \cdot 9$ variant in populations $5-12$.

\section{Distribution of mIDNA RFLPS}

Only Moreton-type mtDNA was found in a sample of 27 individuals from site 11 within the area in which introgression of Moreton mtDNA has pre-

of a sample of 15 individuals from a site $60 \mathrm{~km}$ north (site 8) of the northern-most Moreton mtDNA-containing population reported previously been reported (Marchant, 1988). One but Moreton mtDNA was not detected further north than this (table 1). Moreton mtDNA was also not detected in three sites west of the previously reported introgressed area (sites 7,9 and 12 ), although the small sample sizes from these sites do not allow us to preclude its presence at low frequencies.

\section{Allozyme variation}

Table 2 shows the frequencies of alleles of the four loci from the three sites analysed. Also shown are frequencies of alleles from two Moreton populations and one Torresian population, reported by Daly et al., (1981), for comparison.

\section{Chromosomal analysis}

The karyotypes of all five embryos showed all acroor telocentric chromosomes, with centromeric, but no interstitial, C-bands, exactly as has been reported for the Torresian subspecies (Shaw et al., 1976; Arnold and Shaw, 1985).

\section{DISCUSSION}

There are a number of lines of evidence that make us believe that the "Moreton" markers found in the Torresian taxon are present as a result of introgression, rather than being due to primary polymorphisms in the latter taxon. The overall concordance between the distribution patterns of allozymes, rDNA and mtDNA, with "Moreton" markers of all types being found in some of the populations, and "Moreton" markers being all absent in several northern ones, is consistent with introgression. "Moreton" mtDNA (Marchant 1988) and allozyme markers (Arnold et al., 1987; Wilkinson, unpublished) are also absent from Torresian in the Northern Territory and Papua. Phylogenies based on allozymes group these areas more closely to Queensland Torresian than any Torresians are to Moreton, and a phylogeny of mtDNA shows that the mtDNA from Northern Territory and Papua has separated from the Queensland Torresian lineages much more recently than the separation of Torresian and Moreton (Marchant, unpublished). These findings indicate (for mtDNA, less convincingly for allozymes, and by inference, for rDNA) that the Torresian/Moreton interaction has come about after secondary contact (see Thorpe 1984).

As with other studies (e.g. Powell, 1983; Boursot et al., 1984; Arnold et al., 1987b; Tegelstrom 1987), the extent of introgression varies when cytoplasmic and nuclear elements are compared. Thus, although Moreton rDNA, allozyme and mtDNA markers are present in populations north of the present-day hybrid zone, the rDNA markers occur more than $200 \mathrm{~km}$ further north than the mtDNA. Likewise, the Moreton allozymic markers occur at least $100 \mathrm{~km}$ further north than the Moreton mtDNA.

There would appear to be two possible explanations for the introgression of the Moreton genetic material into the Torresian populations: (a) the introduction of the Moreton variants could have originated from or near the present-day hybrid zone (now in the Mary River Heads region), or, (b) the ancient distribution of the Moreton 
Table 2 Frequencies of Moreton and Torresian diagnostic allozymes for three Torresian populations

\begin{tabular}{|c|c|c|c|c|c|c|c|c|}
\hline \multirow[t]{4}{*}{ Site 11} & $c$ & $77.5 \%$ & $e$ & $82 \cdot 5 \%$ & $c$ & $85 \cdot 0 \%$ & $c$ & $80.0 \%$ \\
\hline & $* d$ & $20 \cdot 0 \%$ & $* g$ & $12 \cdot 5 \%$ & $* b$ & $15 \cdot 0 \%$ & $* b$ & $17 \cdot 5 \%$ \\
\hline & $a$ & $2 \cdot 5 \%$ & $c$ & $2 \cdot 5 \%$ & & & $? e$ & $2.5 \%$ \\
\hline & & & $d$ & $2 \cdot 5 \%$ & & & & \\
\hline \multirow[t]{2}{*}{ Site 6} & $c$ & $100 \cdot 0 \%$ & $e$ & $92.5 \%$ & $c$ & $100 \cdot 0 \%$ & $c$ & $75.0 \%$ \\
\hline & & & $* g$ & $5.0 \%$ & & & $* b$ & $25.0 \%$ \\
\hline \multirow[t]{3}{*}{ Site 3} & $c$ & $100 \cdot 0 \%$ & $e$ & $100 \cdot 0 \%$ & $c$ & $95 \cdot 0 \%$ & $c$ & $95.0 \%$ \\
\hline & & & & & ${ }^{*} b$ & $5.0 \%$ & ${ }^{*} b$ & $2.5 \%$ \\
\hline & & & & & & & $? e$ & $2.5 \%$ \\
\hline \multirow{4}{*}{$\begin{array}{l}\text { Site } 18 \dagger \\
\quad \text { (Torr.) }\end{array}$} & $b$ & $7 \cdot 0 \%$ & $c$ & $2 \cdot 0 \%$ & $b$ & $11.0 \%$ & $c$ & $4.0 \%$ \\
\hline & $c$ & $83 \cdot 0 \%$ & $e$ & $91.0 \%$ & $c$ & $89.0 \%$ & $c$ & $96.0 \%$ \\
\hline & $d$ & $11 \cdot 0 \%$ & $g$ & $4.0 \%$ & & & & \\
\hline & & & $i$ & $2 \cdot 0 \%$ & & & & \\
\hline \multirow{4}{*}{$\begin{array}{l}\text { Site } 17 \dagger \\
\text { (Mor.) }\end{array}$} & $c$ & $2.0 \%$ & $e$ & $11 \cdot 0 \%$ & $b$ & $97 \cdot 0 \%$ & & $2.0 \%$ \\
\hline & $d$ & $98.0 \%$ & $f$ & $2 \cdot 0 \%$ & $c$ & $3.0 \%$ & $b$ & $98.0 \%$ \\
\hline & & & $g$ & $77 \cdot 0 \%$ & & & & \\
\hline & & & $h$ & $4.0 \%$ & & & & \\
\hline \multirow{2}{*}{$\begin{array}{l}\text { Fraser Island } \dagger \\
\quad \text { (Moreton) }\end{array}$} & $d$ & $100 \cdot 0 \%$ & $e$ & $48.0 \%$ & $b$ & $100 \cdot 0 \%$ & $b$ & $100 \cdot 0 \%$ \\
\hline & & & $\mathrm{g}$ & $52.0 \%$ & & & & \\
\hline
\end{tabular}

$N=20$ for sites 11,6 and 3 .

* indicates Moreton allele.

? uncertain whether this electromorph is the same as the $e$ allele previously reported (Daly et al., 1981) to be present in the Daintree taxon.

† Daly et al., 1981.

subspecies may have included a region north of its present distribution. The former explanation would require the spread of Moreton rDNA, allozymes and mtDNA markers for distances of approximately $450 \mathrm{~km}, 350 \mathrm{~km}$ and $250 \mathrm{~km}$, respectively. This whole-scale asymmetrical introgression of Moreton variants into the Torresian form would, we believe, necessitate the invoking of quite strong selection for each of the Moreton markers (which have disparate biochemical functions). Although selection may have played a role in determining the frequency of some of the Moreton genetic markers in the Torresian populations (see below), we do not believe that this is the most likely cause of the present distribution of these variants. The most tenable argument would seem to be that the initial introduction of the Moreton markers into Torresian individuals was facilitated by the presence of the Moreton subspecies within this region. We would also suggest that the same pattern of asymmetrical introgression of the Moreton rDNA, mtDNA and allozyme markers across the existing hybrid zone (Arnold et al., 1987a; Marchant et al., in preparation) could be explained by the movement of the zone in a predominantly easterly direction. Shaw et al. (1985) have discussed the lack of any movement of the zone over a six year period. However, this most recent data suggest that large- scale movement does occur, albeit over a much longer time scale.

\section{Frequency of Moreton rDNA, mtDNA and allozyme markers in the Torresian subspecies}

Theoretical work (Moran, 1981), and results from computer modelling (Marchant, unpublished data), have indicated that selectively neutral genetic markers can indeed be left behind a moving zone. Near to the hybrid zone, the Moreton allozyme markers for the GOT-2 and IDH-1 loci show a pattern of asymmetrical introgression into the Torresian subspecies (Marchant et al., in preparation). By comparison, the Moreton PGI marker does not demonstrate such a pattern. For the two populations north of the Moreton distribution that show significant levels of Moreton allozyme variants, population 11 possesses all three markers at high frequencies while population 6 possesses only the Moreton PGI marker at significant levels. This distribution of variants would, we believe, be best explained by an assumption of neutrality for the allozyme markers examined, since no allozyme marker shows consistently elevated frequencies in the introgressed regions (Daly et al., 1981; this study; Marchant, et al. in preparation). 
The occurrence of the Moreton mtDNA in the range of the Torresian subspecies has been previously reported (Marchant, 1988). The data presented here define the limits of mtDNA introgression, and the larger sample sizes within the introgressed area confirm that the foreign mtDNA is fixed there. Although the presence of these variants in the Torresian populations can be best explained by hybrid zone movement and the subsequent "trailing" of the mtDNA variants, the apparent fixation of these mtDNA variants characteristic of the Moreton subspecies within the Torresian populations cannot be accounted for simply by past movement of the zone. A stochastic process such as a population bottleneck which led to the fixation of the Moreton mtDNA in an introgressed Torresian population and the expansion of this population into the present-day area of introgression might explain our findings (as has recently been proposed by Gyllensten and Wilson, 1987 for the Mus mtDNA introgression). However, the presence of at least two mtDNA "clones", which are also found in the Moreton and the more southerly South East Australian taxon (Marchant, 1988) in these populations, would argue against such a historical explanation (although it should be recorded here that these two types differ by only a single restriction site, which might have been convergently lost or gained in one of them). It is of interest to note that the random extinction (and presumably the fixation) of mitochondrial mutants can proceed at a much faster rate due to the unique population genetics of these cytoplasmic elements (Advise et al., 1984).

With respect to the mtDNA pattern of geographic variation, the Moreton rDNA shows a similar frequency distribution in the Torresian populations (Arnold et al., 1987a; Marchant, 1988; Marchant et al., in preparation). Near the present-day hybrid zone (sites $13,16,18,19$ ), the Moreton rDNA variant is found at frequencies of $0-0 \cdot 17$, while in the Torresian populations north of the zone the populational frequencies of the Moreton type vary from 0.37-1.0 (e.g. see fig. 3). As with the mtDNA, zone movement alone cannot explain the elevated levels of the Moreton rDNA variant in the populations north of the zone. Arnold et al. (1987a) have argued that there are two possible explanations for the asymmetrical introgression of the rDNA variants into the Torresian populations proximal to the zone: (1) biased gene conversion favouring the Moreton rDNA variant and/or (2) natural selection for the Moreton rDNA loci themselves or the Moreton nucleolar organizing chromosomes. If, as we have suggested, the presence of the Moreton rDNA variants are mainly a result of movement of the hybrid zone rather than penetration of a stationary zone, then populations that are most distant from the present-day contact zone would have possessed the Moreton variants for the longest period of time. Furthermore, if biased gene conversion and/or natural selection have been major factors involved in the frequency increase of the Moreton rDNA variant in the Torresian populations, then the longer a population has possessed the Moreton variant the higher its frequency should be. Thus, the pattern illustrated in fig. 3 is directly explicable on the basis of the past introduction of the Moreton variant into the Torresian subspecies, via zone movement, followed by biased gene conversion that favoured the Moreton variant. It is important to note that the process of gene conversion has been experimentally demonstrated in eukaryotes (Klein, 1984; Hilliker et al., 1987). Likewise, the biased nature of some intragenic conversion events has also been documented (Leblon, 1972). Furthermore, data from a recent study of $C$. captiva individuals from Torresian populations near the hybrid zone have indicated that gene conversion is likely to have played a role in the introgression and maintenance of the Moreton rDNA variant within the Torresian populations (Arnold, et al., 1988).

Recent studies of the "non-transcribed" spacer region of the rDNA locus of Xenopus have demonstrated a functional role for this rDNA component: repeated sequences within the spacer enhance transcription (Moss, 1983). Thus, the greater the number of enhancer repeats adjacent to the rDNA promoter sequence, the greater is the level of transcription (Reeder, 1984). Furthermore, when two genes containing different numbers of enhancer elements are coinjected into oocytes, the gene with the greatest number of these elements is always transcribed preferentially (Moss, 1983; Reeder et $a l ., 1983)$. In relation to the present findings, it is conceivable that the Moreton spacer elements are not only favoured in a biased gene conversion process, but are also dominant in a transcriptional sense. If this is found to be the case, then it is plausible that under certain conditions individuals carrying such a transcriptional unit might be favoured by selection because of their ability to modulate protein production more rapidly. Experiments that will result in a measurement of the levels of ribosomal RNA produced from the Moreton and Torresian rDNA loci in $F_{1}$ hybrids will be facilitated by using DNA oligonucleotides specific to the two rDNA types. 
Introgression of nuclear and cytoplasmic elements and the concept of the coadapted genome

In order to investigate the components of hybrid inviability involved in the products of Moreton $x$ Torresian crosses, Coates and Shaw (1982) examined the pattern of meiotic recombination in $F_{1}$ hybrids. This analysis demonstrated a major perturbation in the positioning of chiasmata that was directly attributable to the pericentric inversion differences between these two taxa. Therefore, it was concluded that a large proportion of the total inviability of the $F_{2}$ generation was due to the aberrant meiotic recombination in the $F_{1}$ hybrids (Coates and Shaw, 1982). Two additional findings support this conclusion. Firstly, the surviving embryos generated from backcrosses of the $F_{1}$ hybrids to either of the parental types do not contain the expected proportion of recombined chromosomes, given the known frequencies of recombination in $F_{1}$ meiosis (Shaw et al., 1982). The deviation from the expected frequencies was entirely the result of intrachromosomal interactions (Shaw et al., 1982). Secondly, Coates and Shaw (1984) carried out experimental crosses involving the Torresian and Moreton chromosomal forms and a third chromosomal form named the "Lakes Entrance" taxon. This latter taxon is characterized by an acrocentric karyotype similar to that of Torresian individuals, but it is allozymically indistinguishable from Moreton, and it contains the numerous interstitial C-bands common in the Moreton subspecies (Coates and Shaw, 1984). These authors found that crosses involving either Moreton or Torresian individuals with the Lakes Entrance form resulted in approximately 50 per cent $\mathrm{F}_{2}$ inviability. The disruption in the positioning of chiasmata (in comparison to the control crosses) was seen in the Moreton $\times$ Lakes Entrance $F_{1}$ hybrids, but not in the Torresian $x$ Lakes Entrance $F_{1}$ 's. From these findings it was concluded that the pericentric rearrangement differences present between the Moreton versus the Torresian and Lakes Entrance taxa result in an approximately 50 per cent reduction in $F_{2}$ viability and it was suggested that the remaining reduction in $\mathrm{F}_{2}$ viability was associated with the "genic" differentiation (as measured by allozyme analysis) between the Torresian versus the Moreton and Lakes Entrance taxa (Coates and Shaw, 1984). These conclusions led to the suggestion that there is strong selection against the disruption of coadapted cis-acting gene complexes present within the $C$. captiva chromosomal taxa (note that coadaptation between chromosomes, maintained by balancing selection, is not being proposed). In the present analysis we have not detected any Moreton chromosomal characters (i.e. pericentric rearrangements or interstitial C-band heterochromatin) in a population that possesses Moreton rDNA, mtDNA and allozymic markers. Our findings of no chromosomal introgression in this region is in accordance with previous karyotypic analyses (Shaw et al., 1987 and unpublished data) and is consistent with the conclusion that there is strong selection against the disturbance of "coadapted cis-acting gene complexes".

Our data would suggest that some genic correlates of observable allozymic differences between the Torresian and Moreton taxa do not contribute to the lack of hybrid fitness. However, the differences in the amount and/or distribution of C-band heterochromatin between the two taxa may very well play a role in the overall reduction of hybrid fitness. In this regard, Arnold et al. (1986) and Arnold and Shaw (1985) have shown that a major component of the C-band heterochromatin present in Moreton individuals consists of a $168 \mathrm{bp}$ highly repeated DNA sequence. This repeated sequence is also found in the Torresian and the Lakes Entrance taxa. Nucleotide sequence data from 49 individual repeats from this sequence family resulted in the identification of a significantly long stretch of conserved bases (Arnold et al., 1986). The conservation of this sequence along with the presence of a unique structure (i.e. dyad symmetry) within this region, led to the conclusion that at least a portion of each " $168 \mathrm{bp}$ " repeat might be under selective constraints (Arnold et al., 1986).

Findings from previous analyses and the present study support the action of selective constraints that ensure the integrity of the internally coadapted nature of the Moreton and Torresian genomes. However, our analysis indicates that other genomic components are not necessarily involved in this coadaptation.

Acknowledgements We would like to thank Dr D. D. Shaw for valuable discussion and criticism of the manuscript. MLA was supported by a Postdoctoral Fellowship from the ANU, and ADM by an Australian Commonwealth Postgraduate Research Award.

\section{REFERENCES}

ARNOLD, M. L. 1986. The heterochromatin of grasshoppers from the Caledia captiva species complex. III. Cytological organisation and sequence evolution in a dispersed highly repeated DNA family. Chromosoma, 94, 183-188. 
ARNOLD, M. L., APPELS, R. AND SHAW, D. D. 1986. The heterochromatin of grasshoppers from the Caledia captiva species complex. I. Sequence evolution and conservation in a highly repeated DNA family. Mol. Biol. Evol., 3, 29-43.

ARNOLD, M. L., CONTRERAS, N. AND SHAW, D. D. 1987. Biased gene conversion and asymmetrical introgression between subspecies. Chromosoma, 96, 368-371.

ARNOLD, M. L. AND SHAW, D. D. 1985. The heterochromatin of grasshoppers from the Caledia captiva species complex. II. Cytological organization of tandemly repeated DNA sequences. Chromosoma, 93, 183-190.

ARNOLD, M. L., SHAW, D. D. AND CONTRERAS, N. $1987 a$. Ribosomal RNA encoding DNA introgression across a narrow hybrid zone between two subspecies of grasshopper. Proc. Natl. Acad. Sci. USA, 84, 3946-3950.

ARNOLD, M. L., WILKINSON, P., SHAW, D. D., MARCHANT, A. D. AND CONTRERAS, N. $1987 b$. Highly repeated DNA and allozyme variation between sibling species: evidence for introgression. Genome, 29, 272-279.

AVISE, J. C., NEIGEL, J. E. AND AR NOLD, J. 1984. Demographic influences on mitochondrial DNA lineage survivorship in animal populations. J. Mol. Evol, 20, 99-105.

BOURSOT, P., BONHOMME, F., BRITTON-DAVIDIAN, J., CATALAN, J., YONEKAWA, H., ORSINI, P., GUERASIMOV, S. AND THALER, L. 1984. Introgression differentielle des genomes nucleaires et mitochondriaux chez deux semiespeces europeennes des souris. C. R. Acad. Sci. Paris, 299, 365-370.

COATES, D. J. AND SHAW, D. D. 1982. The chromosomal component of reproductive isolation in the grasshopper Caledia captiva. I. Meiotic analysis of chiasma distribution patterns in two chromosomal taxa and their $F_{1}$ hybrids. Chromosoma, 86, 509-531.

COATES, D. J. AND SHAW, D. D. 1984. The chromosomal component of reproductive isolation in the grasshopper Caledia captiva. III. Chiasma distribution patterns in a new chromosomal taxon. Heredity, 53, 85-100.

DALY, J. C., WILKINSON, P. AND SHAW, D. D. 1981. Reproductive isolation in relation to allozymic and chromosomal differentiation in the grasshopper Caledia captiva. Evolution, 35, 1164-1179.

GYLLENSTEN, U. AND WILSON, A. C. 1987. Interspecific mitochondrial DNA transfer and the colonization of Scandinavia by mice. Genet. Res., 49, 25-29.

HILliKER, A. J., CLARK, S. H. AND CHOVNICK, A. 1987. Genetic analysis of intragenic recombination in Drosophila. In Low, K. B. (ed.) Recombination of Genetic Material, Academic Press, New York (In press).

KLEIN, H. L. 1984. Lack of association between intrachromosomal gene conversion and reciprocal exchange. Nature, $310,748-753$.

LEBLON, G. 1972. Mechanism of gene conversion in Ascobolus immersus. I. Existence of a correlation between the origin of mutants induced by different mutagens and their conversion spectrum. Molec. Gen. Genetics, 115, 36-48.

MARCHANT, A. D. 1988. Apparent introgression of mitochondrial DNA across a narrow hybrid zone in the Caledia captiva species-complex. Heredity, 60, 39-46.

MORAN, C. 1979. The structure of the hybrid zone in Caledia captiva. Heredity, 42, 13-32.

MORAN, C. 1981. Genetic demarcation of geographical distribution by hybrid zones. Proc. Ecol. Soc. Aust., 11, 67-73.
MORAN, C. AND SHAW, D. D. 1977. Population cytogenetics of the genus Caledia (Orthoptera: Acridinae). III. Chromosomal polymorphism, racial parapatry and introgression. chromosoma, 63, 181-204.

MORAN, C., WHLKINSON, P. AND SHAw, D. D. 1980. Allozyme variation across a narrow hybrid zone in the grasshopper Caledia captiva. Heredity, 44, 69-81.

MOSS, T. 1983. A transcriptional function for the repetitive ribosomal spacer in Xenopus laevis. Nature, 302, 223-228.

POWELL, J. R. 1983. Interspecific cytoplasmic gene flow in the absence of nuclear gene flow: evidence from Drosophila. Proc. Natl. Acad. Sci. USA, 80, 492-495.

REEDER, R. H. 1984. Enhancers and ribosomal gene spacers. Cell, 38, 349-351.

REEDER, R. H., ROAN, J. G. AND DUNAWAY, M. 1983. Spacer regulation of Xenopus ribosomal gene transcription: competition in oocytes. Cell, 35, 449-456.

SHAW, D. D. AND COATES, D. J. 1983. Chromosomal variation and the concept of the coadapted genome-a direct cytological assessment. In Kew Chromosome Conference. II. Brandham, P. E. and Bennett, M. D. (eds). Allen and Unwin, London, pp. 207-216.

SHAW, D. D., COATES, D. J., ARNOLD, M. L. AND WILKINSON, P. 1985. Temporal variation in the chromosomal structure of a hybrid zone and its relationship to karyotypic repatterning. Heredity, 55, 293-306.

SHAW, D. D., MARCHANT, A. D., ARNOLD, M. L. AND CONTRERAS, N. 1987. Chromosomal rearrangements, ribosomal genes and mitochondrial DNA: contrasting patterns of introgression across a narrow hybrid zone. In Brandham, P. E. and Bennett, M. D. (eds). Kew Chromosome Conference. III. Allen and Unwin, London (In press).

SHAW, D. D., MORAN, C. AND WILKINSON, P. 1980. Chromosomal reorganisation, geographic differentiation and the mechanism of speciation in the genus Caledia. In Blackman, R. L., Hewitt, G. M. and Ashburner, M. (eds). Royal Entomological Society Symposium X Insect Cytogenetics. Blackwell, Oxford, pp. 171-194.

SHAW, D. D., WEBB, G. C. AND WILKInSON, P. 1976. Population cytogenetics of the genus Caledia (Orthoptera: Acridinae). II. Variation in the pattern of C-banding. Chromosoma, 56, 169-190.

SHAW, D. D. AND WILKINSON, P. 1980. chromosome differentiation, hybrid breakdown and the maintenance of a narrow hybrid zone in Caledia. Chromosoma, 80, 1-31.

SHAW, D. D., WILKINSON, P. AND COATES, D. J. 1982. The chromosomal component of reproductive isolation in the grasshopper Caledia captiva. II. The relative viabilities of recombinant and non-recombinant chromosomes during embryogenesis. Chromosoma, 86, 533-549.

SHAW, D. D., WILKINSON, P. AND MORAN, C. 1979. A comparison of chromosomal and allozymal variation across a narrow hybrid zone in the grasshopper Caledia captiva. Chromosoma, 75, 333-351.

TEGELSTROM. H. 1987. Transfer of mitochondrial DNA from the northern red-bellied vole (Clethrionomys rutilus) to the bank vole (C. glareolus). J. Mol. Evol. 24, 218-22.

THORPE, R. S. 1984. Primary and secondary transition zones in speciation and population differentiation: a phylogenetic analysis of range expansion. Evolution, 38, 233-243. 